\title{
Effect of Active Smoking During Pregnancy on Women and Newborn Health
}

\author{
Emre Yanikkerem ${ }^{1,}$, Semra $A y^{2}$ and Selda İldan Çalım ${ }^{1}$ \\ ${ }^{1}$ Celal Bayar University, School of Health, Istasyon mevki, Manisa, 45010, Turkey \\ ${ }^{2}$ Celal Bayar University, Vocational School of Health, Manisa, Uncubozköy kampüsü, 45010, Turkey
}

\begin{abstract}
The aim of the study was to identify the effect of prenatal smoking on mother and newborn health. The study was carried out in 700 women, who delivered at Merkez Efendi Maternity and Children's Hospital between $1^{\text {st }}$ January, 2011 and $31^{\text {st }}$ December, 2011.

Of the sample of women, $15.6 \%$ were current and $7.3 \%$ were quitting smokers. Women who continued smoking during pregnancy lived in households with husband who smoked and had higher rates of depressive symptoms and pregnancy included hypertension. Smoker women more likely reported to expose physical violence during pregnancy by their partner. Meconium in amniotic fluid was associated with women smoking status. Newborns who were exposed to tobacco smoke prenatally had deficits in weight $(-186.6 \mathrm{gr})$, height $(-0.9 \mathrm{~cm})$ and head circumference at birth $(-0.6 \mathrm{~cm})$. In the study when women quit smoking during the first trimester, their infants have anthropometric measures similar to infants of nonsmokers.

Smoking during pregnancy was related to low birth weight, height, and with small head circumference. Smoking cessation during pregnancy may have a greater impact on baby anthropometrics measures which were similar to infants of nonsmokers. To protect the health of their future unborn children, it would be optimal to target all women of reproductive age to quit smoking before they consider becoming pregnant.
\end{abstract}

Keywords: Smoking, prenatal smoking, smoking during pregnancy, anthropometric measures, newborn health.

\section{INTRODUCTION}

Smoking prevalence rates have been steadily increasing in developing countries, while the prevalence of smoking has been slowly declining in the developed countries over the past 20 years [1]. The prevalence of smoking during pregnancy was found, $12 \%$ in the United States [2] and in Germany [3], 15\% in the United Kingdom [4], 19.6\% in Spain [5], 22.7\% in Italy [6], 30\% in Poland [7], and $37.2 \%$ in Serbia [8]. Turkey Demographic and Health Survey (TDHS) in 2008 results show that $30 \%$ of ever-married women and $22 \%$ of women were currently smoking. This proportion for cigarette use among ever-married women has increased since the TDHS-2003 (28\%). Considering maternity status, one in ten pregnant women currently smoke and $17 \%$ of women who are breastfeeding are currently using cigarette [9].

Active smoking is a big threat to the health of women, fetus and children. Smoking during pregnancy increases the risk of harmful pregnancy outcomes, such as impaired fecundability, increased risk of pregnancy and prenatal period complications [10], premature rupture of membranes [11], placenta previa [12] abruption placenta [13] and preterm delivery [14]

*Address correspondence to this author at the Celal Bayar University, School of Health, İstasyon mevki, Manisa, 45010, Turkey; Tel: +9002362318373; Fax: +9002362320058; E-mail: emrenurse@hotmail.com and gender-specific health risks, including cervical cancer, osteoporosis, poor pregnancy outcome and early menopause. Tobacco related diseases are on the rise in women, considering the fact that more women now die of lung cancer than breast cancer [1].

It is well known that the habit of smoking during pregnancy result in higher rates of spontaneous abortions, ectopic pregnancies, stillbirths, fetal growth restriction [11, 15-18]. Maternal smoking during pregnancy impairs fetal growth [19,20], affected vital signs at birth (as shown by lower Apgar scores) [11], increased morbidity of neonates and respiratory, circulatory and neurological disorders in neonates, infants and older children [10] and shortens gestation causing premature birth $[18,21]$.

Cigarette smoking is also responsible for many complications including low-birth weight (LBW) infants $[5,15,17-23]$ and deaths from Sudden Infant Death Syndrome [11, 24]. Some of studies investigated relationship between smoking during pregnancy and growth measures at birth and these measures decreased the number of cigarettes smoked per day $[15,25-28]$.

In order to define the women who smoked during pregnancy and to determine the identification of prevalence and detrimental effects of smoking is crucial. Data on the prevalence, predictors and 
detrimental effects of mother and child is limited in Turkey. In our country, there was a little research about the effect of smoking during pregnancy to the health of the mother or fetus. Maternal smoking during pregnancy is associated with a reduction in birth size but in Turkey, very few studies have collated changes in neonatal anthropometry according to baby gender, women's pre-pregnancy body mass index (BMI), and smoking status of women during pregnancy [15, 29, 30]. Baby's birth weight may vary according to the gender of the baby, mother's body mass index and smoking during pregnancy. In the study we evaluated the anthropometrics measures of the babies according to these parameters.

The aim of the study was (1) to assess smoking prevalence among pregnant women, (2) to compare the women characteristics between smoking mothers and non-smoking ones, (3) to examine the adverse effects of smoking on the health of women for pregnancy problems and obstetric complications, (4) to investigate the effect of maternal smoking during pregnancy on birth outcomes such as anthropometrics measures of the babies mainly their birth weight, height, head circumferences, and Apgar scores.

\section{METHODS}

\section{Design and Participants}

The study was undertaken at Merkez Efendi Maternity and Children's Hospital between $1^{\text {st }}$ January, 2011 and $31^{\text {st }}$ December, 2011. The inclusion criterion were, having a healthy baby, and being able to understand and speak sufficient Turkish to answer the interview questions. Infants who were babies of diabetic mothers and multiple pregnancies were excluded $(n=18)$. We reached 734 women and invited them to take part in the study. Twenty-one of the women did not want to participate and 13 women did not fully complete the questionnaire. These women were excluded from the study. The sample of research consisted of 700 women to be interviewed on the first or second day after delivery in the department of obstetrics at the hospital.

\section{Questionnaire}

The study questionnaire included four parts. The first part of questionnaire included thirteen questions, seven included in women socio-demographic characteristics, six included women reproductive characteristics. That is, age (stratified according to the mean age), educational level (illiterate, primary school, secondary and high school or above), occupation, income status of the family (high income defining income over expenditure, middle defining equality of the income and expenditure and low income defining income less than expenses), family type (patriarchal or nuclear), health insurance, and BMI, parity, history of spontaneous and induced abortion, pregnancy intention (planned and unplanned), whether she had a private doctor during her pregnancy or not, and mode of delivery.

Section two contained to questions about problems or complication of the current pregnancy (miscarriage threat, risk of premature birth, premature rupture of membranes, and pregnancy included hypertension$\mathrm{PIH}$, heartburn and regurgitation). The part also included questions about women's psychological health (for two questions "did you feel depressed and unhappy during and before pregnancy?") and history of physical violence during pregnancy by their partner.

Third part composed questions about women's smoking status which was determined of self-reports. To obtain this information, women were first asked about current and past cigarette use. Three groups were defined in terms of women smoking status as following: non-smoking group (women reported no smoking ever, either before or during their present pregnancy), quitters (women who declared smoked during pregnancy and had stopped smoking in the first trimester), and a smoking group (women reported smoked during all pregnancy period). In addition, women who currently and smoke cigarettes were asked about age at smoking initiation and the number of cigarettes they smoked each day. There were also questions in the part concerning the smoking habits of her partner and the occurrence of passive smoking at home. We evaluated of smoking status just retrospective questions.

The last part of the questionnaire included the anthropometrics measures of the babies mainly their weight, height, head circumferences and Apgar scores. Anthropometric assessment was collected from hospital records. Measurements with standardized measurement tools were made by trained health personnel. The state of newborn babies was assessed according to the APGAR scale and the score ranges from $0-10$. The scale is used to determine the physical status of an infant immediately after childbirth: at 1 and 5 minutes after birth, with the following criteria: appearance, pulse, grimace, activity, respiration [7]. 
The data also included baby gender and meconium in amniotic fluid during birth.

\section{Ethics of the Research}

This study has been approved by the Ethics Committee of the Faculty of Medicine, Celal Bayar University. The study protocol and consent procedure was approved by the administrative authorities of Manisa Health Directors. Written informed consent was obtained from all participating mothers. The aims of the study were explained to mothers. Those who did not wish to participate in the study were thanked for their time and told that their refusal would not affect their care.

\section{Analysis}

The data were analyzed using the Statistical Package for Social Sciences (SPSS 17.0 version). Basic descriptive statistics and frequency calculations were performed on all variables. Smoking status (active, quitting and non-smokers) was assessed for the women's characteristics, pregnancy problems or complications and infant's anthropometric measures. Chi-square test was used to assess statistical differences between categorical variables by smoking status. ANOVA test was carried out to describe the relation between mother's smoking habit and baby's weight, height, head circumference and Apgar score. All the analyses were carried out separately for boys and girls. A $p$-level of $<0.05$ was considered statistically significant.

\section{RESULTS}

Of the 734 eligible women, 700 (95.4\%) agreed to participate in the study and completed the questionnaires.

\section{Characteristics of Women According to Smoking Status}

Socio-demographic and obstetric characteristics of the women are shown in Table 1. The mean age of the women was 26.6 \pm 5.1 years (minimum 18 years and maximum 45 years). Of the participating women, $46.7 \%$ had primary school education and $10.9 \%$ were employed, $11.9 \%$ were in the low income level group and $29.1 \%$ were living in patriarchal family type. Reproductive history showed that almost one-thirds of the respondents were primiparous $(33.9 \%)$. Of the women, 173 (24.7\%) reported having had an unplanned pregnancy. Overall, $40.9 \%$ of the women had a private doctor during pregnancy.
Of the sample of women, $23.3 \%$ of the women had smoked before their current pregnancy, 109 women (15.6\%) were active smokers and 540 women (77.1\%) were non-smokers. However, only 51 women (7.3\%) had quit smoking during pregnancy (Table $\mathbf{1}$ ).

The mean age of starting smoking was $17.3 \pm 3.7$ years for active smokers, $17.1 \pm 5.6$ for quitter smokers. The women smoked on average 9 cigarettes per day. In the study, 82 (75.2\%) mothers was decelerated smoking one to nine cigarettes a day, and 27 (24.8\%) mothers smoking $>$ or $=10$ cigarettes a day. Among of women smoking (active and quitter women) through their pregnancies, 111 (69.4\%) women got the information from health care professionals about harmful effect of smoking (data not shown).

There was no statistical difference between the smoker's, nonsmoker's women and women who stopped smoking during pregnancy in terms of women age, education level, employment status, family income, family type, health insurance and parity. The findings showed that maternal characteristics were similar according to women's smoking status $(p>0.05)$.

Among the total number of respondents, $57.4 \%$ were exposed during pregnancy to passive smoking at their home by the partner. Women who continue to smoke during pregnancy are more likely to have a partner who smoked compared with those who never smoked. About half of the women (52.2\%) who never smokers reported that there was a smoker partner in their house compared to $77.1 \%$ of women who were smoking during pregnancy $(p<0.05)$. A similar pattern was observed for whether visitors (family / friends) were allowed to smoke in their homes. Over half of the women $(66.1 \%)$ who smoked during pregnancy said smoking was allowed in their home compared to $40.9 \%$ never smoked women $(p<0.05)$.

\section{Complications or Problems During Pregnancy According to Smoking Status}

About one out of five smokers $(21.1 \%)$ stated that they had $\mathrm{PIH}$ during pregnancy and $\mathrm{PIH}$ was associated with women smoking status $(p<0.05)$. The smoker women seemed to be the group with more depressive compared to nonsmokers before pregnancy. Smokers also reported to feel depressed during pregnancy $(p<0.05)$. Smoker women were more likely to have experienced physical violence in their pregnancy period than non- smokers $(p<0.05)$. Approximately one out of ten smokers and quitter 
Table 1: Smoking During Pregnancy According to Women Characteristics

\begin{tabular}{|c|c|c|c|c|c|}
\hline \multirow{3}{*}{ Characteristic of women } & \multirow{3}{*}{$n=700$} & \multicolumn{3}{|c|}{ Smoking status during pregnancy } & \multirow{3}{*}{$\begin{array}{c}\text { Test } \\
\text { p value }\end{array}$} \\
\hline & & \multirow{2}{*}{$\begin{array}{c}\begin{array}{c}\text { Active } \\
\text { smokers }\end{array} \\
n=109 \\
(15.6 \%)\end{array}$} & \multirow{2}{*}{$\begin{array}{c}\begin{array}{c}\text { Quitting } \\
\text { smokers }\end{array} \\
\mathrm{n}=51(7.3 \%)\end{array}$} & \multirow{2}{*}{$\begin{array}{c}\text { Non-smokers } \\
n=540 \\
(77.1 \%)\end{array}$} & \\
\hline & & & & & \\
\hline \multicolumn{6}{|l|}{ Age of women } \\
\hline$\leq 25$ years old & $311(44.4)$ & $43(39.4)$ & $16(31.4)$ & $252(46.7)$ & $\chi^{2}=5.711$ \\
\hline \multicolumn{6}{|l|}{ Education level of women } \\
\hline Not illiterate & $113(16.1)$ & $24(22.0)$ & $7(13.7)$ & $82(15.2)$ & \\
\hline Primary & $327(46.7)$ & 45 (41.3) & $24(47.1)$ & $258(47.8)$ & \\
\hline Secondary & $141(20.1)$ & $25(22.9)$ & $7(13.7)$ & $109(20.2)$ & $\chi^{2}=7.950$ \\
\hline High school or above & $119(17.0)$ & $15(13.8)$ & $13(25.5)$ & $91(16.9)$ & $p=0.242$ \\
\hline \multicolumn{6}{|l|}{ Perceived income level } \\
\hline Low & $83(11.9)$ & $20(18.3)$ & $5(9.8)$ & $58(10.7)$ & \\
\hline Middle & $506(72.2)$ & $74(67.9)$ & $39(76.5)$ & $393(72.8)$ & $\chi^{2}=5.637$ \\
\hline High & $111(15.9)$ & $15(13.8)$ & $7(13.7)$ & $89(16.5)$ & $\mathrm{p}=0.228$ \\
\hline \multicolumn{6}{|l|}{ Health insurance } \\
\hline Yes & $78(11.1)$ & $16(14.7)$ & $5(9.8)$ & $57(10.6)$ & $\chi^{2}=1.657$ \\
\hline No & $622(88.9)$ & $93(85.3)$ & $46(90.2)$ & $483(89.4)$ & $p=0.437$ \\
\hline \multicolumn{6}{|l|}{ Family type } \\
\hline Nuclear family & $496(70.9)$ & $75(68.8)$ & $41(80.4)$ & $380(70.4)$ & $\chi^{2}=2.529$ \\
\hline Patriarchal family & $204(29.1)$ & $34(31.2)$ & $10(19.6)$ & $160(29.6)$ & $\mathrm{p}=0.282$ \\
\hline \multicolumn{6}{|l|}{ History of spontaneous abortion } \\
\hline Yes & $78(11.1)$ & $13(11.9)$ & $6(11.8)$ & $59(10.9)$ & $\chi^{2}=0.113$ \\
\hline No & $622(88.9)$ & $96(88.1)$ & $45(88.2)$ & $481(89.1)$ & $p=0.945$ \\
\hline \multicolumn{6}{|l|}{ Pregnancy intention } \\
\hline Planned & $527(75.3)$ & $73(67.0)$ & $40(78.4)$ & $414(76.7)$ & $\chi^{2}=4.873$ \\
\hline Unplanned & $173(24.7)$ & $36(33.0)$ & $11(21.6)$ & $126(23.3)$ & $p=0.087$ \\
\hline \multicolumn{6}{|l|}{ Women had private doctor } \\
\hline Yes & $286(40.9)$ & 34 (31.2) & $20(39.2)$ & $232(43.0)$ & $\chi^{2}=5.261$ \\
\hline No & $414(59.1)$ & $75(68.8)$ & $31(608)$ & $308(57.0)$ & $\mathrm{p}=0.072$ \\
\hline \multicolumn{6}{|l|}{ Mode of delivery } \\
\hline Normal & $369(52.7)$ & $63(57.8)$ & $22(43.1)$ & $284(52.6)$ & \\
\hline Volunteer C/S & $185(26.4)$ & $23(21.1)$ & 17 (33.3) & $145(26.9)$ & $\chi^{2}=3.752$ \\
\hline Emergency CS & $146(20.9)$ & $23(21.1)$ & $12(23.5)$ & $111(20.6)$ & $\mathrm{p}=0.441$ \\
\hline \multicolumn{6}{|l|}{ Smoking partner } \\
\hline Yes & $402(57.4)$ & $84(77.1)$ & $36(70.6)$ & $282(52.2)$ & $\chi^{2}=26.789$ \\
\hline No & $298(42.6)$ & $25(22.9)$ & $15(29.4)$ & $258(47.8)$ & $p=0.000$ \\
\hline \multicolumn{6}{|l|}{ BMI } \\
\hline Low $(<19.8)$ & $121(17.3)$ & $28(25.7)$ & $13(25.5)$ & $80(14.8)$ & \\
\hline Normal (19.8-26.0) & $383(54.7)$ & $47(43.1)$ & $19(37.3)$ & $317(58.7)$ & \\
\hline High (26.1-29.0) & $107(15.3)$ & $17(15.6)$ & $12(23.5)$ & $78(14.4)$ & $\chi^{2}=18.908$ \\
\hline Obese (>29.0) & $89(12.7)$ & $17(15.6)$ & 7 (13.7) & $65(12.0)$ & $p=0.004$ \\
\hline
\end{tabular}


Table 2: Comparison Various Problems and Complications During Pregnancy According to Smoking Status

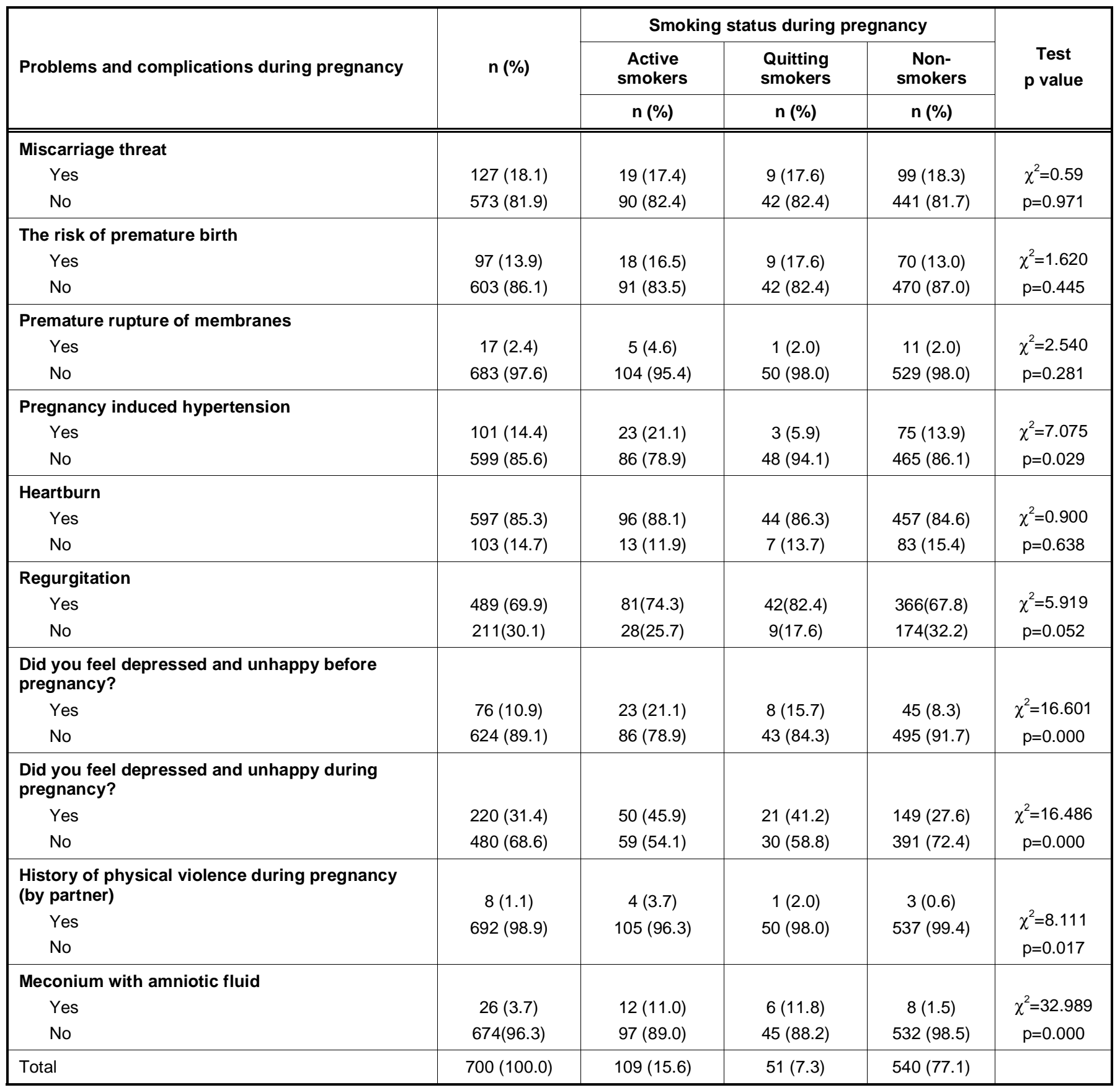

women (11\%, $11.8 \%$ respectively) had meconium with amniotic fluid during birth, while only $1.5 \%$ nonsmokers women had $(p<0.05)$ (Table 2).

The Anthropometrics Measures of the Babies at Birth According Baby Gender and the Smoking Status

Anthropometric measures at birth according to baby gender and women's status of smoking were presented in Table 3. A significant difference was found between mean of weights, heights and head circumferences. Birth weights were $3175.0 \pm 489.9 \mathrm{~g}$ for infants who born to smokers women and $3361.6 \pm 454.6 \mathrm{~g}$ for the nonsmokers $(p<0.05)$. Baby whose mothers had been quitting smoking during pregnancy had higher birth weight (3329.4 \pm 474.3$)$. In the study, the average reduction in birth weight seen in smoking women was found 186.6 grams. The mean birth weight for girl newborns was $2996.6 \mathrm{~g}$ in infants of smokers and $3299.6 \mathrm{gr}$ in infants of nonsmokers. The differences (- 
Table 3: The Anthropometrics Measures of the Babies at Birth According to Baby Gender and the Smoking Status

\begin{tabular}{|c|c|c|c|c|c|}
\hline \multirow{3}{*}{ Anthropometrics measures } & \multicolumn{3}{|c|}{ Smoking status during pregnancy } & \multirow{2}{*}{ Total } & \multirow{3}{*}{ Test } \\
\hline & Active smokers & Quitting smokers & Non-smokers & & \\
\hline & Mean \pm SD & Mean $\pm S D$ & Mean \pm SD & Mean \pm SD & \\
\hline Mean of weight & $3175.0 \pm 489.9$ & $3329.4 \pm 474.3$ & $3361.6 \pm 454.6$ & $3330.2 \pm 465.9$ & $\begin{array}{l}F=7.408 \\
p=0.001\end{array}$ \\
\hline Mean of weight (for girl) & $2996.6 \pm 415.9$ & $3190.4 \pm 423.7$ & $3299.6 \pm 435.5$ & $3249.2 \pm 443.5$ & $\begin{array}{c}F=10.067 \\
p=0.000\end{array}$ \\
\hline Mean of weight (for boy) & $3310.3 \pm 501.3$ & $3463.0 \pm 489.6$ & $3421.4 \pm 465.3$ & $3405.4 \pm 474.1$ & $\begin{array}{l}F=1.602 \\
p=0.203\end{array}$ \\
\hline Mean of height & $49.8 \pm 2.4$ & $50.6 \pm 2.1$ & $50.7 \pm 1.9$ & $50.6 \pm 2.1$ & $\begin{array}{l}F=9.456 \\
p=0.000\end{array}$ \\
\hline Mean of height (for girl) & $49.1 \pm 2.7$ & $50.2 \pm 2.2$ & $50.5 \pm 2.0$ & $50.3 \pm 2.2$ & $\begin{array}{l}F=8.135 \\
p=0.000\end{array}$ \\
\hline Mean of weight (for boy) & $50.3 \pm 2.1$ & $50.9 \pm 1.9$ & $50.9 \pm 1.9$ & $50.9 \pm 1.9$ & $\begin{array}{l}F=3.091 \\
p=0.047\end{array}$ \\
\hline $\begin{array}{l}\text { Mean of head } \\
\text { circumferences }\end{array}$ & $34.2 \pm 1.3$ & $34.9 \pm 1.3$ & $34.8 \pm 1.3$ & $34.7 \pm 1.3$ & $\begin{array}{c}F=10.308 \\
p=0.000\end{array}$ \\
\hline $\begin{array}{l}\text { Mean of head circumferences } \\
\text { (for girl) }\end{array}$ & $33.8 \pm 1.2$ & $34.6 \pm 1.4$ & $34.6 \pm 1.3$ & $34.5 \pm 1.3$ & $\begin{array}{l}F=6.674 \\
p=0.001\end{array}$ \\
\hline $\begin{array}{l}\text { Mean of head circumferences } \\
\text { (for boy) }\end{array}$ & $34.5 \pm 1.2$ & $35.2 \pm 1.2$ & $35.1 \pm 1.2$ & $34.9 \pm 1.3$ & $\begin{array}{l}F=5.437 \\
p=0.005\end{array}$ \\
\hline $\begin{array}{l}\text { Mean of Apgar scores } \\
\text { (1. minute) }\end{array}$ & $7.9 \pm 0.6$ & $7.8 \pm 0.7$ & $8.0 \pm 0.4$ & $7.9 \pm 0.1$ & $\begin{array}{l}F=8.641 \\
p=0.000\end{array}$ \\
\hline $\begin{array}{l}\text { Mean of Apgar scores } \\
\text { (1. minute for girl) }\end{array}$ & $7.9 \pm 0.5$ & $7.8 \pm 0.7$ & $8.0 \pm 0.4$ & $7.9 \pm 0.5$ & $\begin{array}{l}F=4.124 \\
p=0.017\end{array}$ \\
\hline $\begin{array}{l}\text { Mean of Apgar scores } \\
\text { (1. minute for boy) }\end{array}$ & $7.9 \pm 0.7$ & $7.8 \pm 0.7$ & $8.0 \pm 0.3$ & $7.9 \pm 0.5$ & $\begin{array}{l}F=4.498 \\
p=0.012\end{array}$ \\
\hline $\begin{array}{l}\text { Mean of Apgar scores } \\
\text { (5. minute) }\end{array}$ & $9.9 \pm 0.6$ & $9.8 \pm 0.5$ & $10.0 \pm 0.5$ & $9.9 \pm 0.5$ & $\begin{array}{l}F=2.703 \\
p=0.068\end{array}$ \\
\hline $\begin{array}{l}\text { Mean of Apgar scores } \\
\text { (5. minute for girl) }\end{array}$ & $9.9 \pm 0.4$ & $9.8 \pm 0.6$ & $9.9 \pm 0.3$ & $9.9 \pm 0.4$ & $\begin{array}{l}F=1.896 \\
p=0.152\end{array}$ \\
\hline $\begin{array}{l}\text { Mean of Apgar scores } \\
\text { (5. minute for boy) }\end{array}$ & $9.8 \pm 0.7$ & $9.8 \pm 0.5$ & $9.7 \pm 0.5$ & $9.9 \pm 0.6$ & $\begin{array}{l}F=1.254 \\
p=0.287\end{array}$ \\
\hline
\end{tabular}

$303.0 \mathrm{~g})$ was statistically significant $(\mathrm{p}<0.05)$. However, boy infants of smoker women during pregnancy were detected to have a birth weight differences of $-111.1 \mathrm{~g}$ with the infants of non-smokers, but the difference was not statistically significant ( $p>0.05$ ) (Table 3 ). The overall difference in mean birth weight between nonsmoking and heavy smokers (women who smoke $>10$ cigarettes a day) was $273.8 \mathrm{~g}$ (data not shown).

In the study birth height differences between groups were statistically significant and we found an important difference in height of infants born to mothers who smoked during their pregnancies $(-0.9 \mathrm{~cm})$ compared to non-smokers' infants. Babies born to mothers who quit smoking during pregnancy had similar height babies who never smoked $(p<0.05)$. When we compared newborns' height at birth, the difference between infants of smokers and nonsmokers women was found -1.4 and $-0.6 \mathrm{~cm}$ for girls and boys respectively, which was a statistically significant $(p<0.05)$.

Smoking during pregnancy was related to with small head circumference. The average head circumference of babies born to women who were smoking, had stopped and never smoking were 34.2, 34.9 and 34.8 respectively $(p<0.05)$. The mean head circumference of babies of nonsmoker was $34.6 \mathrm{~cm}$ for girls and $35.1 \mathrm{~cm}$ 
for boys. In infant born to smoker women the head circumference were reduced by 0.8 and $0.6 \mathrm{~cm}$, respectively; the head circumference of baby with nonsmokers was similar in baby born to quitters.

A statistically significant correlation was found between smoking during pregnancy and evaluation of the babies according to the APGAR score for first minutes $(p<0.05)$. The relationship between APGAR score for five minutes and women smoking status was not statistically significant $(p>0.05)$.

\section{DISCUSSION}

Cigarette smoking during pregnancy is an important public health problem hurts women's health, causes pregnancy complications, increases the risk of health problems in newborns, and leads to negative consequences for child health. Although the study data was limited to a cohort of in Manisa and smoking status was self reported the study provides important findings about effect of smoking during pregnancy.

\section{Characteristics of Women According to Smoking Status}

In the study, $15.6 \%$ of the women stated that they smoked cigarette during pregnancy and only $7.3 \%$ reported quitting spontaneously during pregnancy. The prevalence of smoking during pregnancy in our study was lower than in most studies of smoking in pregnancy in Italy, Spain, Serbia and Poland [5-8], it was similar to the rates in a study carried out in the United States, Germany and United Kingdom [2-4]. Smoking cessation interventions targeting pregnant women are needed in Turkey. Effective interventions to help women to stop smoking during pregnancy could reduce the risk of adverse obstetric and pregnancy outcomes. Health care professionals should inform their patients about possible risks related to high-risk behaviors during preconception counseling or during the first obstetric visit.

In the study, all women characteristics were not associated with smoking during pregnancy. In contrast to our findings, previous studies have found that women in low-income groups [8, 31, 32], younger women $[5,8,33]$, unmarried status previous, induced abortion [6], and lower education [5, 6, 8, 15] were related with cigarette consumption.

In the study, continued smoking during pregnancy has been shown to be significantly more common among women with a smoker partner. There was also a significant link with between smoking during pregnancy and smoking to allow in the homes. A woman was more like to have smoked during her pregnancy if there were smokers in her social environment. Similarly, previous studies reported that having a partner who smoked the key factors that contribute to smoking during pregnancy [8]. Qualitative study was conducted with 60 pregnant Maori women the women all lived with smokers which reportedly made it harder to quit; most of them lived in a smoky environment, where family, friends and coworkers smoked [34]. In Turkey, one study stated that $69.2 \%$ of the women were exposed to passive smoking at home [30]. Health professionals should target cessation programmers at both pregnant women and their partners. The partner should help the pregnant women to stop even if he is a smoker himself. He should be informed about the informed about the importance of his support for stopped smoking during pregnancy.

\section{Complications or Problems During Pregnancy According to Smoking Status}

In this study, smoker women reported experiencing more depression than nonsmoking women before and during pregnancy. Cigarette smoking and depressive mood are highly co-morbid; however, the mechanism underlying this association is poorly understood. Cigarette smokers often report that smoking can alleviate feelings of depression; thus feeling depressed may cause people to smoke as a way of self medicating. If smoking causes depressive mood, women who continue to smoke through pregnancy should report higher levels of depressed mood than those who stop smoking. However; if low mood rendered it difficult for women to give up smoking the same association would be seen [35]. One study found that stressful life events were associated with smoking cessation, and mental health variables may be important to successful prenatal smoking cessation [36]. In United States one study stated that prenatal depressive symptoms are associated with maternal smoking and may be a barrier to smoking cessation [37]. Lynch et al. (2011) found that mothers who smoke in pregnancy are likely to experience higher levels of psychological symptoms, which, in turn, predict higher levels of parenting stress [38].

In the present study smoker women were more likely to have physically violence during pregnancy by partner. A study among American Indians current smokers also report being neglected and physically abused in childhood and adolescence [39]. Smoking in 
pregnancy may be a marker for symptoms of psychological distress in mothers. Understanding the factors associated with smoking will help to bring about policy changes and more effective programs to address the problem of high smoking rates.

The study findings showed that smoker women had $\mathrm{PIH}$ and meconium with amniotic fluid than nonsmokers. In Australia, one study stated that mothers who continued to smoke in subsequent pregnancies were more likely to have adverse pregnancy outcomes compared with others [40].

\section{Anthropometrics Measures at Birth According to Baby Gender and Smoking Status}

Infants from non-smoking mothers were heavier, longer, and body circumferences were all larger than those from smoking mothers. In the study, a doseeffect relation between number of cigarettes smoked by a pregnant women and her infant's weight has been shown, especially heavy smokers had at increased risk of experiencing LBW. Maternal smoking during pregnancy is an important risk factor for growth retardation and previous studies stated that there was a remarkable reduction for birth weight (100- $300 \mathrm{~g}$ ) between smokers and non-smokers' infant and these studies' findings are similar to our study's findings [5, $15,17-23,29,32,33]$.

In the findings of the study, we evaluated the relationship between women's pre-pregnancy BMI and babies anthropometrics measures. As women's BMI increased, the baby's weight, height and head circumference also increased. Similarly one study stated that smoking during pregnancy is strongly associated with increased risk of small for gestational age (SGA) and low birth weight, whereas elevated prepregnancy $\mathrm{BMI}$ is associated with a decreased risk of SGA and greater birth weight [25].

It is important note the study found that when women quit smoking during the first trimester, their infants have weight measurement similar to infants of nonsmokers. The finding tells us there is more time than we thought to help the mothers change their behavior during pregnancy. Quitting in smoking has a beneficial effect on increasing average birth weight and decreasing the incidence of LBW infants. This result was found similar to other studies [35, 41]. This is a significant public health concern because low birth weight is the most important single determinant of neonatal and infant morbidity and mortality. Pregnancy provides us with a window in which, rather than women stopping smoking for personal health reasons, there are women who stop smoking high numbers because of concern for the health of their offspring. One study also stated that smoking during pregnancy was strongly associated with LBW and SGA [17]. Health care professionals should carry out educational programs to increase awareness and understanding of pregnant women and their husbands about the harmful effects of smoking on birth outcomes.

In the present study, babies Apgar score in the first minute were found statistically significant according to women smoking status. In UK, one study state that pregnant women exposed to passive smoking during pregnancy bear children obtaining lower scores according to the APGAR score [7].

The birth height and head circumference of infants born to mothers who smoked during their pregnancies were found to be respectively, $0.9 \mathrm{~cm}$ and $0.6 \mathrm{~cm}$ less than the measures of infants born to non- smokers. In infant born to smoker women height at birth were reduced by 1.4 (for girls) and 0.6 (for boys) $\mathrm{cm}$. Compared newborns' height at birth for gender, the difference between infants of smokers and nonsmokers women was found -0.8 and $-0.6 \mathrm{~cm}$ for girls and boys respectively. Similar findings reported to other studies $[15,16,26,27]$. Contrary to our findings one study in Turkey, the smoking habit of the mother did not significantly influence the head circumference and height measurements of the babies, although the values are lower than the newborns of non-smoking mother [29].

In conclusion, smoker women reported experiencing more depression than nonsmoking women before and during pregnancy. Smoking during pregnancy was related to low birth weight, height, with small head circumference and low APGAR score. Smoking cessation during pregnancy may have a greater impact on baby anthropometrics measures which were similar to infants of nonsmokers.

This study has important clinical implications. To protect the health of their future unborn children, it would be optimal to target all women of reproductive age to quit smoking before they consider becoming pregnant. If a woman is smoking at the time of her first prenatal visit, every effort should be made to encourage her to quit and stay smoke-free. Continuing smoking during pregnancy was associated with depression before or during pregnancy. Healthcare 
providers should provide information about effect of smoking during pregnancy for mother and newborn health. Prenatal counseling to women for depressive symptoms and encouraging the quit of smoking are important.

\section{REFERENCES}

[1] Kaleta D, Usidame B, Polanska K. Tobacco advertisements targeted on women: creating an awareness among women. Cent Eur J Public Health 2011; 19(2): 73-8.

[2] Tong VT, Jones JR, Dietz PM, D'Angelo D, Bombard JM. Centers for Disease Control and Prevention (CDC) Trends in smoking before, during, and after pregnancy - Pregnancy Risk Assessment Monitoring System (PRAMS), United States, 31 sites, 2000-2005. Morbidity and Mortality Weekly Report Surveillance Summaries 2009; 58(4): 1-29.

[3] Meyer S, Raisig A, Gortner L, Ong MF, Bücheler M, Tutdibi E. In utero tobacco exposure: the effects of heavy and very heavy smoking on the rate of SGA infants in the Federal State of Saarland, Germany. Eur J Obstet Gynecol Reprod Biol 2009; 146(1): 37-40. http://dx.doi.org/10.1016/j.ejogrb.2009.05.031

[4] Crozier SR, Robinson SM, Borland SE, Godfrey KM, Cooper C, Inskip HM. SWS Study Group. Do women change their health behaviours in pregnancy? Findings from the Southampton Women's Survey. Paediatr Perinat Epidemiol 2009; 23(5): 446-53. http://dx.doi.org/10.1111/j.1365-3016.2009.01036.x

[5] Delgado-Peña YP, Rodríguez-Martínez G, SamperVillagrasa MP, et al. Socio-cultural, obstetric and anthropometric characteristics of newborn children of mothers who smoke in Spain. Asociación Española de Pediatría 2012; 76(1): 4-9.

[6] De-Santis M, De-Luca C, Mappa I, Quattrocchi T, Angelo, L, Cesari E. Smoke, alcohol consumption and illicit drug use in an Italian population of pregnant women. Eur J Obstet Gynecol Reprod Biol 2011; 159(1): 106-10. http://dx.doi.org/10.1016/j.ejogrb.2011.07.042

Wdowiak A, Wiktor $\mathrm{H}$, Wdowiak L. Maternal passive smoking during pregnancy and neonatal health. Ann Agric Environ Med 2009; 16(2): 309-12.

[8] Krstev S, Marinković J, Simić S., Kocev N, Bondy SJ. Prevalence and predictors of smoking and quitting during pregnancy in Serbia: results of a nationally representative survey. Int J Public Health 2012; 57(6): 875-83. http://dx.doi.org/10.1007/s00038-011-0301-5

[9] Turkey Demographic and Health Survey. Hacettepe University Institute of Population Studies 2008. Available at: http: //www.hips.hacettepe.edu.tr/eng/tdhs08/ (accessed 12 December 2012).

[10] Perz S, Gaca M, Mniszak M, Wesół D. Smoking prevalence during pregnancy and exposition of infants to environmental tobacco smoke. Przegl Lek 2006; 63(10): 1063-5.

[11] Hayashi K, Matsuda Y, Kawamichi Y, Shiozaki A, Saito S. Smoking during pregnancy increases risks of various obstetric complications: a case-cohort study of the Japan Perinatal Registry Network database. Am J Epidemiol 2011; 21(1): 61-6.

http://dx.doi.org/10.2188/jea.JE20100092

[12] Oyelese Y, Smulian JC. Placenta previa, placenta accreta, and vaso previa. Obstetr Gynecol 2006; 107: 927-41. http://dx.doi.org/10.1097/01.AOG.0000207559.15715.98

[13] Tikkanen M, Nuutila M, Hiilesmaa V, Paavonen J, Ylikorkala O. Prepregnancy risk factors for placental abruption. Acta Obstet Gynecol Scand 2006; 85: 40-44. http://dx.doi.org/10.1080/00016340500324241
[14] Nq SP, Zelikoff JT. Smoking during pregnancy: subsequent effects on offspring immune competence and disease vulnerability in later life. Reproductive Toxicol 2007; 23: 428437.

http://dx.doi.org/10.1016/j.reprotox.2006.11.008

[15] Fenercioglu AK, Tamer I, Karatekin G, Nuhoglu A. Impaired postnatal growth of infants prenatally exposed to cigarette smoking. Tohoku J Exp Med 2009; 218(3): 221-8. http://dx.doi.org/10.1620/tjem.218.221

[16] Ingvarsson RF, Bjarnason AO, Dagbjartsson A, Hardardottir $\mathrm{H}$, Haraldsson A Thorkelsson $\mathrm{T}$. The effects of smoking in pregnancy on factors influencing fetal growth. Acta Paediatr 2007; 96(3): 383-6.

http://dx.doi.org/10.1111/j.1651-2227.2007.00103.x

[17] Villalbí JR, Salvador J. Cano-Serral G, Rodríguez-Sanz MC, Borrell C. Maternal smoking, social class and outcomes of pregnancy. Paediatr Perinat Epidemiol 2007; 21(5): 441-7. http://dx.doi.org/10.1111/j.1365-3016.2007.00845.x

[18] Vogazianos $P$, Fiala J, Vogazianos M. The influence of active maternal smoking during pregnancy on birth weights in Cyprus. Cent Eur J Public Health 2005; 13(2): 78-84.

[19] Ward C, Lewis S, Coleman T. Prevalence of maternal smoking and environmental tobacco smoke exposure during pregnancy and impact on birth weight: retrospective study using Millennium Cohort. BMC Public Health 2007; 16: 7-81.

[20] Matsubara F, Kida M, Tamakoshi A, Wakai K, Kawamura T, Ohno $Y$. Maternal active and passive smoking and fetal growth: A prospective study in Nagoya, Japan. J Epidemiol 2000; 10(5): 335-43 http://dx.doi.org/10.2188/jea.10.335

[21] Wills RA, Coory MD. Effect of smoking among Indigenous and non-Indigenous mothers on preterm birth and full-term low birthweight. Med J Aust 2008; 189(9): 490-4.

[22] Machado-Jde B, Plínio-Filho VM, Petersen GO, Chatkin JM. Quantitative effects of tobacco smoking exposure on the maternal-fetal circulation. BMC Pregnancy Childbirth 2011; 31: 11-24

[23] Bachir R, Chaaya M. Maternal smoking: Determinants and associated morbidity in two areas in Lebanon. Matern Child Health J 2008; 12: 298-307. http://dx.doi.org/10.1007/s10995-007-0242-z

[24] Salihu HM, Wilson RE. Epidemiology of prenatal smoking and perinatal outcomes. Early Human Development 2007; 83: 713-720.

http://dx.doi.org/10.1016/i.earlhumdev.2007.08.002

[25] La-Merrill M, Stein, CR, Landrigan P, Engel SM, Savitz DA Prepregnancy body mass index, smoking during pregnancy, and infant birth weight. Ann Epidemiol 2011; 21(6): 413-20. http://dx.doi.org/10.1016/j.annepidem.2010.11.012

[26] Hindmarsh PC, Geary MP, Rodeck CH, Kingdom JC, Cole TJ. Factors predicting ante- and postnatal growth. Pediatr Res 2008; 63(1): 99-102. http://dx.doi.org/10.1203/PDR.0b013e31815b8e8f

[27] Vielwerth SE, Jensen RB, Larsen T, Greisen G. The impact of maternal smoking on fetal and infant growth. Early Human Development 2007; 83(8): 491-5.

http://dx.doi.org/10.1016/j.earlhumdev.2006.09.010

[28] Steyn K, de Wet T, Saloojee Y, Nel H, Yach D. The influence of maternal cigarette smoking, snuff use and passive smoking on pregnancy outcomes: the Birth to ten study. Paediatr Perinat Epidemiol 2006; 20(2): 90-9. http://dx.doi.org/10.1111/j.1365-3016.2006.00707.x

[29] Durualp E, Bektas, G Ergin D, Karaca E, Topcu E. A study on the relationship between cigarette smoking of the mothers and the newborn's weight, height, and head circumference measurements. Ankara Universitesi Tıp Fakultesi Mecmuası 2011; 64(3): 119-126.

[30] Karcaaltincaba D, Kandemir O, Yalvac S, Güven ES, Yildirim BA, Haberal A. Cigarette smoking and pregnancy: results of 
a survey at a Turkish women's hospital in 1,020 patients. $J$ Obstet Gynaecol 2009; 29(6): 480-6. http://dx.doi.org/10.1080/01443610902984953

[31] Thrift AP, Nancarrow H, Bauman AE. Maternal smoking during pregnancy among Aboriginal women in New South Wales is linked to social gradient. Aust N Z J Public Health 2011; 35(4): 337-42. http://dx.doi.org/10.1111/j.1753-6405.2011.00728.x

[32] Adamek R, Florek E, Piekoszewski W, Anholcer A, Kaczmarek E. Effect of exposure to tobacco smoke and selected socioeconomic factors in occurrence of low birth weight. Przegl Lek 2005; 62(10): 965-9.

[33] Samper MP, Jiménez-Muro A, Nerín I, Marqueta A, Ventura $\mathrm{P}$, Rodríguez $\mathrm{G}$. Maternal active smoking and newborn body composition. Early Human Development 2012; 88(3): 141-5. http://dx.doi.org/10.1016/j.earlhumdev.2011.07.015

[34] Glover M, Kira A. Why Maori women continue to smoke while pregnant. N Z Med J 2011; 124(1339): 22-31.

[35] Lewis SJ, Araya R, Smith GD, Freathy R, Gunnell D, Palmer $T$, Munafò M. Smoking is associated with, but does not cause, depressed mood in pregnancy--a mendelian randomization study. PLoS 2011; 6(7): e21689. http://dx.doi.org/10.1371/journal.pone.0021689

[36] Gyllstrom ME, Hellerstedt WL, Hennrikus D. The association of maternal mental health with prenatal smoking cessation and postpartum relapse in a population-based sample. Matern Child Health J 2012; 16(3): 685-93.

http://dx.doi.org/10.1007/s10995-011-0764-2
[37]

Orr ST, Blazer DG, Orr CA. Maternal prenatal depressive symptoms, nicotine addiction, and smoking-related knowledge, attitudes, beliefs, and behaviors. Matern Child Health J 2012; 16(5): 973-8.

http://dx.doi.org/10.1007/s10995-011-0822-9

[38] Lynch ME, Johnson KC, Kable JA, Carroll J, Coles CD. Smoking in pregnancy and parenting stress: maternal psychological symptoms and socioeconomic status as potential mediating variables. Nicotine Tobacco Res 2011; 13(7): 532-9. http://dx.doi.org/10.1093/ntr/ntr037

[39] Hodge F, Nandy K. Factors associated with American Indian cigarette smoking in rural settings. Int $\mathrm{J}$ Environ Res Public Health 2011; 8(4): 944-54.

[40] Mohsin M, Jalaludin B. Influence of previous pregnancy outcomes and continued smoking on subsequent pregnancy outcomes: an exploratory study in Australia. Int $\mathrm{J}$ Gynaecol Obstet 2008; 115(11): 1428-35 http://dx.doi.org/10.1111/j.1471-0528.2008.01864.x

[41] Bailey BA, McCook JG, Hodge A, McGrady L. Infant birth outcomes among substance using women: Why quitting smoking during pregnancy is just as important as quitting illicit drug use. Matern Child Health J 2012; 16(2): 414-22. http://dx.doi.org/10.1007/s10995-011-0776-y 